\title{
Urine sampling techniques in symptomatic primary-care patients: a diagnostic accuracy review
}

\author{
Anne Holm ${ }^{*}$ and Rune Aabenhus
}

\begin{abstract}
Background: Choice of urine sampling technique in urinary tract infection may impact diagnostic accuracy and thus lead to possible over- or undertreatment. Currently no evidencebased consensus exists regarding correct sampling technique of urine from women with symptoms of urinary tract infection in primary care. The aim of this study was to determine the accuracy of urine culture from different sampling-techniques in symptomatic non-pregnant women in primary care.

Methods: A systematic review was conducted by searching Medline and Embase for clinical studies conducted in primary care using a randomized or paired design to compare the result of urine culture obtained with two or more collection techniques in adult, female, non-pregnant patients with symptoms of urinary tract infection. We evaluated quality of the studies and compared accuracy based on dichotomized outcomes.

Results: We included seven studies investigating urine sampling technique in 1062 symptomatic patients in primary care. Mid-stream-clean-catch had a positive predictive value of 0.79 to 0.95 and a negative predictive value close to 1 compared to sterile techniques. Two randomized controlled trials found no difference in infection rate between mid-stream-clean-catch, mid-stream-urine and random samples.

Conclusions: At present, no evidence suggests that sampling technique affects the accuracy of the microbiological diagnosis in non-pregnant women with symptoms of urinary tract infection in primary care. However, the evidence presented is in-direct and the difference between mid-stream-clean-catch, mid-stream-urine and random samples remains to be investigated in a paired design to verify the present findings.
\end{abstract}

Keywords: "Urinary tract infections" [Mesh], "Urine" [Mesh], "Specimen handling" [Mesh], "Urine specimen collection" [Mesh], "Primary health care" [Mesh], "General practice" [Mesh]

\section{Background}

Symptomatic urinary tract infection (UTI) in women is a common condition in general practice, and every day general practitioners or their staff instruct women in delivering urine samples for examination [1]. The main concern when sampling urine is that inadequate handling may increase the risk of contamination in turn leading to overdiagnosis and overtreatment of UTI. Sterile collection of urine samples can be performed using suprapubic puncture or urethral catheterization and use of these collection techniques could possibly reduce

\footnotetext{
* Correspondence: anneholm@sund.ku.dk

Research Unit for General Practice and Section of General Practice,

Department of Public Health, University of Copenhagen, Øster Farimagsgade 5, PO box 2099, 1014 Copenhagen, Denmark
}

contamination and thereby overdiagnosis and overtreatment. However, in a primary care setting these methods are considered obsolete today due to the associated discomfort for the patient and a minor risk of iatrogenic infection and other complications. Current methods include i) mid-stream-clean-catch technique (MSCC) where the patient is instructed to clean the labia before voiding using tap water, soap or disinfectants, ii) midstream urine (MSU) without prior cleaning, iii) random samples delivered without instruction or iv) homevoided samples with or without standardized transport media. These sampling techniques are mostly based on tradition or expert opinion and ease-of-use for patient and doctor rather than stringent evidence. A study from 2000 conducted in primary care found no evidence that 
sampling technique affected contamination rate or infection rate in urine samples [2], but new evidence within this area is often questioned and debated [3-5]. Since sampling techniques (MSCC, MSU, random samples and home voiding) differ extensively in preparation time and discomfort, ease-of-use for doctors as well as their patients, it is relevant to review their diagnostic yield. The aim of this study was to conduct a systematic review to determine the accuracy of urine culture from different sampling techniques in symptomatic patients in primary care.

\section{Method}

\section{Literature search}

We searched Medline and Embase for clinical studies conducted in primary care published before May 2015 in English, Swedish, Danish or Norwegian. Combinations of the words "urinary tract infection", cystitis, bacteriuria, urine, specimen, handling, urinalysis, collection, midstream and" clean catch" were used. To identify more studies from before 1970, a slightly different search-string was used for the older studies in Medline. The literature search and inclusion of studies was performed by $\mathrm{AH}$. The full search strings can be seen in Appendix A.

\section{Inclusion criteria}

Clinical studies randomizing or using a paired design to compare the result of urine culture obtained with two or more collection techniques in adult, self-helped, nonpregnant (and not post-partum) women with symptoms of UTI in primary care (general practice, outpatients clinics or comparable settings). We did not discriminate between complicated and uncomplicated cases of UTI.

\section{Exclusion criteria}

- Studies investigating mainly patients who were not self-helped, were asymptomatic, pregnant, children or men (wrong group)

- Studies conducted in the secondary sector (wrong setting)

- Studies using other modalities than culture as reference (wrong gold standard)

- Studies where data for the selected outcome was not available (missing data)

- Studies using a different design than described in the inclusion criteria (wrong design)

The references of included studies were screened and experts in the field were contacted to provide additional literature.

\section{Data extraction}

Data from included studies were entered into a dataform with information on setting, number of patients, age, inclusion- and exclusion-criteria for the study, reference and index text, the assigned cut off for infection vs. contamination, the bacteria identified and study design. Data on absolute numbers of infected urine samples, true and false positives and negatives or predictive values of one sampling method versus another were likewise extracted from the included studies. If these measures were not directly provided in the article, we calculated them if possible. Selected outcomes were dichotomized for the planned analyses as negative/positive culture. Culture results presented as equivocal and contaminated were grouped with the negative results. Data from the relevant patients were extracted when studies also included patients covered by the exclusion criteria. Data extraction was done by both authors and discrepancies were discussed and corrected. When data was not available or incomplete we referred from contacting authors, as most studies were more than 10 years old.

\section{Definition of reference standard}

Assuming an increasing contamination rate in the order of: 1) Suprapubic puncture, 2) urethral catheterization samples, 3) MSCC, 4) MSU, 5) Random samples, 6) Home-voided urine, the least contaminated was used as reference and the most contaminated as index test. For example, if a study investigated both MSCC and random urine sampling in a paired design, MSCC was used as reference standard and random samples as index test.

\section{Study designs}

This review included both paired studies and randomized controlled trials (RCT). RCTs were analysed separately.

\section{Quality assessment}

The included studies were evaluated using QUADAS-2 for assessment of diagnostic accuracy studies [6]. No study was excluded based on low quality according to this tool. Both studies using paired samples and randomized controlled trials were assessed with QUADAS-2.

\section{Data analysis}

The specified dichotomized outcomes were used to calculate predictive values, sensitivity and specificity in paired studies. The generated sensitivity and specificity values were used to create forest plots on the diagnostic accuracy. Diagnostic accuracy plots were performed using Review Manager (RevMan) Version 5.3. Copenhagen: The Nordic Cochrane Centre, the Cochrane Collaboration, 2014.

\section{Results}

\section{Literature search}

The initial search resulted in 570 titles in Medline and 749 titles in Embase. After review of titles, abstracts and articles we included seven full text articles presenting results 


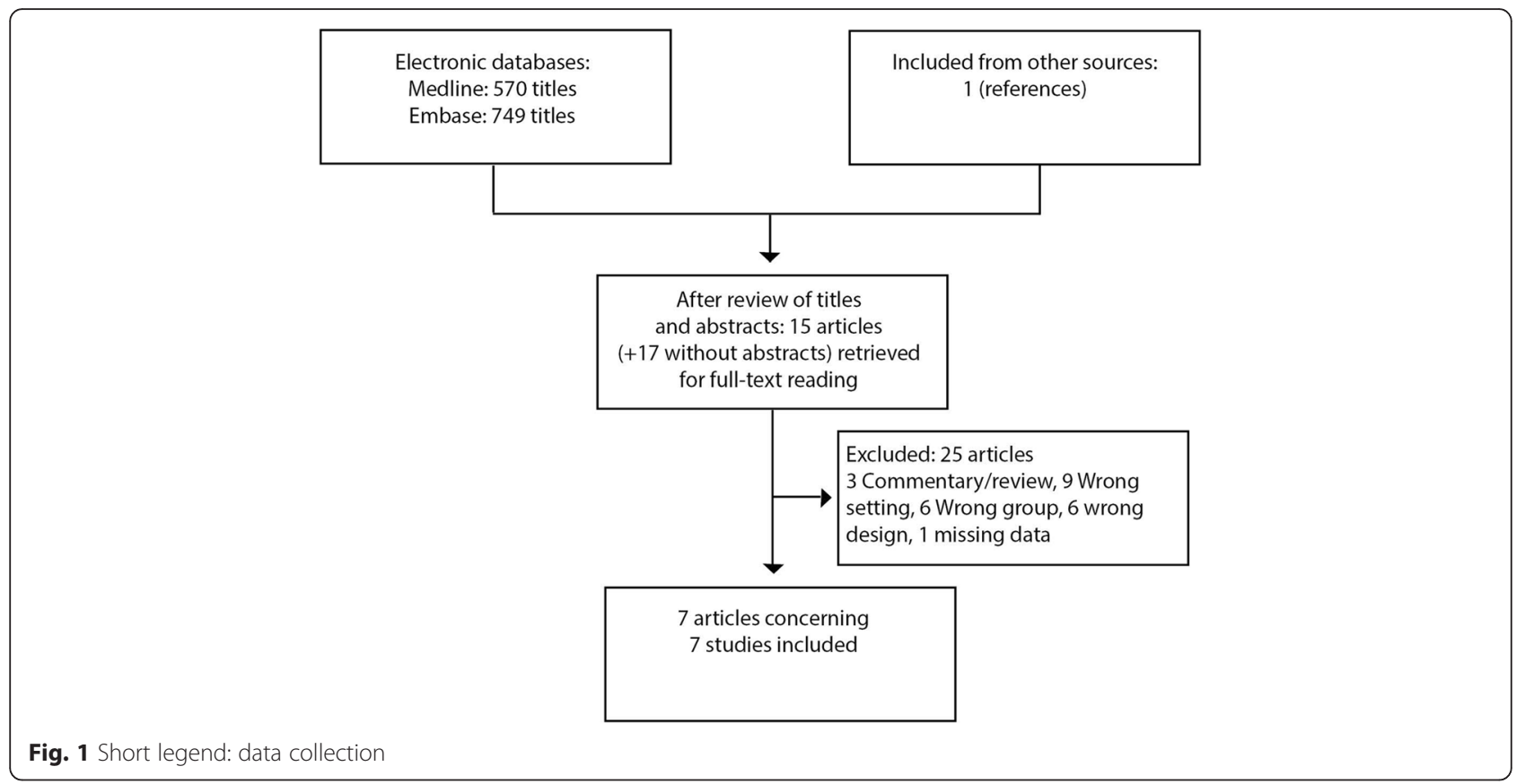

from seven studies investigating urine sampling technique in 1062 non-pregnant women with symptoms of UTI in primary care. A flow diagram of the literature search and review of titles, abstracts, and articles is shown in Fig. 1. Two of the studies were from general practice while the remaining five were from outpatient clinics or student clinics. The included studies are shown in Table 1. A list of excluded studies is provided in Appendix B.

\section{Quality of included studies according to Quadas-2}

The quality of the included studies is summarized in Table 2. Generally the studies were judged to be of moderate to high risk of bias. No study was considered having low risk of bias. The most common error was lack of blinding of the interpreter to the results of the index and reference tests or lack of reporting of blinding. The applicability of the studies was not regarded a general concern. The full quality assessment is described in Additional file 1.

\section{Data from included studies Paired design studies}

Four studies used a paired design to compare MSCC urine samples to samples obtained with urethral catheterization or suprapubic puncture $(n=589)$ [7-10]. Urethral catheterization and suprapubic puncture are essentially sterile techniques and served as reference e.g. gold standard. Two of these studies applied $\geq 10 \mathrm{cfu} / \mathrm{ml}$ as the cut-off for infection in both index- and reference-test, one study used a cut-off of $\geq 10^{5} \mathrm{cfu} / \mathrm{ml}$ and one reported absolute counts for both index- and reference-test (Table 1). The positive predictive value (PPV) of a MSCC sample varied according to the chosen cut-off for infection: cutoff: $\geq 10 \mathrm{cfu} / \mathrm{ml} 0.79$ (0.71-0.86); cutoff: $\geq 10^{5} \mathrm{cfu} / \mathrm{ml} 0.95$ (0.83-

Table 1 Characteristics of included studies

\begin{tabular}{|c|c|c|c|c|c|c|c|}
\hline Study & Setting & Design & Patients (n) & Incidence & Technique & Cutoff index ${ }^{a}$ & Cutoff reference $^{a}$ \\
\hline Hooton 2013 & Outpatient clinic & Paired samples & $202^{b}$ & 0.70 & MSCC vs. Cat & $\geq 10 \mathrm{cfu} / \mathrm{ml}$ & $\geq 10 \mathrm{cfu} / \mathrm{ml}$ \\
\hline Lifshitz 2000 & University clinic & RCT & 242 & 0.55 & Random vs. MSCC & $\geq 10^{2} \mathrm{cfu} / \mathrm{ml}$ & $\geq 10^{2} \mathrm{cfu} / \mathrm{ml}$ \\
\hline Baerheim 1990 & General practice & Paired samples & 73 & 0.74 & Home vs. MSCC & $\geq 10^{4} \mathrm{cfu} / \mathrm{ml}$ & $\geq 10^{4} \mathrm{cfu} / \mathrm{ml}$ \\
\hline Walter 1989 & Outpatient clinic & Paired samples & 105 & 0.40 & MSCC vs. Cat & $\geq 10^{5} \mathrm{cfu} / \mathrm{ml}$ & $\geq 10^{5} \mathrm{cfu} / \mathrm{ml}$ \\
\hline Bradbury 1988 & General practice & RCT & 158 & 0.25 & MSU vs. MSCC & $>10^{5} \mathrm{cfu} / \mathrm{ml}$ & $>10^{5} \mathrm{cfu} / \mathrm{ml}$ \\
\hline Stamm 1982 & $\begin{array}{l}\text { Outpatient } \\
\text { clinic/student clinic }\end{array}$ & Paired samples & 187 & 0.52 & MSCC vs. Cat/Sup & $\begin{array}{l}\text { Reporting } \\
\text { absolute counts }\end{array}$ & $\geq 10 \mathrm{cfu} / \mathrm{ml}$ \\
\hline Mabeck 1969 & Outpatient clinic & Paired samples & 95 & - & MSCC vs. Sup & $\begin{array}{l}\text { Reporting } \\
\text { absolute counts }\end{array}$ & $\begin{array}{l}\text { Reporting } \\
\text { absolute numbers }\end{array}$ \\
\hline
\end{tabular}

Detailed legend: Characteristics of included studies. ${ }^{a}$ The definition has been simplified. ${ }^{\mathrm{b}}$ Reporting the number of samples not patients. ${ }^{\mathrm{C}} \mathrm{MSCC}$ and $\mathrm{MSCC}+\mathrm{vaginal}$ tampoon. RCT Randomized controlled trial; MSCC Mid-stream-clean-catch; MSU Mid-stream-urine; Cat Urethral Catheterization; SUP suprapubic puncture; cfu colony-forming units 
Table 2 Quality of included studies assessed using Qaudas-2

\begin{tabular}{|c|c|c|c|c|c|c|c|}
\hline \multirow[t]{2}{*}{ Study } & \multicolumn{4}{|c|}{ RISK OF BIAS } & \multicolumn{3}{|c|}{ APPLICABILITY CONCERNS } \\
\hline & $\begin{array}{l}\text { PATIENT } \\
\text { SELECTION }\end{array}$ & INDEX TEST & $\begin{array}{l}\text { REFERENCE } \\
\text { STANDARD }\end{array}$ & $\begin{array}{c}\text { FLOW AND } \\
\text { TIMING }\end{array}$ & $\begin{array}{l}\text { PATIENT } \\
\text { SELECTION }\end{array}$ & INDEX TEST & $\begin{array}{l}\text { REFERENCE } \\
\text { STANDARD }\end{array}$ \\
\hline Hooton 2013 & (:) & $?$ & $?$ & (;) & (2) & (:) & (:) \\
\hline Lifshitz 2000 & (-) & (-) & (-); & (2) & (-); & (;) & (;) \\
\hline Baerheim 1990 & $?$ & (:) & (-) & (-) & (2) & (:) & (:) \\
\hline Walter 1989 & (-) & $?$ & $?$ & $?$ & (:) & (-) & ;) \\
\hline Bradbury 1988 & (-) & (;) & (-) & (2) & (-) & (;) & (;) \\
\hline Stamm 1982 & $?$ & $?$ & $?$ & (2) & $?$ & (2) & (:) \\
\hline Mabeck 1969 & $?$ & $?$ & $?$ & (2) & ;) & (:) & ;) \\
\hline
\end{tabular}

Detailed legend: (;) Low Risk :) High Risk ? Unclear Risk

0.99). The negative predictive value of a MSCC was close to 1 in all four studies. The accuracy found in the four studies is shown in Table 3. The achieved specificity was influenced by the selected cut-off levels, with higher thresholds corresponding to increasing specificity. We did not perform a meta-analysis or calculate heterogeneity as the applied cut-offs varied considerable thus impeding a meaningful pooling of the results.

One study investigated home-voided samples against MSCC taken in general practice [11]. This study found a high PPV of home-voided samples of 0.92 (0.81-0.98), but a lower NPV of $0.71(0.48-0.88)$. The results of this study are shown in Table 4.

The studies by Stamm and Mabeck reported absolute counts of colony-forming units in the voided urine samples and this allowed us to investigate the current cut-off for primary uropathogens of $10^{3} \mathrm{cfu} / \mathrm{ml}$ in voided urine samples against $10 \mathrm{cfu} / \mathrm{ml}$ in suprapubic puncture [12]. Using these current cut-offs we calculated the sensitivity of MSCC to be $0.81(0.71-0.88)$ in the study by Stamm and $0.96(0.85-0.99)$ in the study by Mabeck. Corresponding specificities were $0.90(0.82-0.95)$ in the study by Stamm and 0.59 (0.43-0.73) in the study by Mabeck.

\section{Randomized controlled trials}

Two randomized controlled trials were identified comparing MSU or random samples to MSCC with infection rate and contamination rate in the randomization-groups as their primary outcomes (number of patients $=400$ ) $[2,13]$. Because of the randomized design, accuracy could not be calculated from these studies. The studies are shown in Table 5. None of the studies found significant differences in infection rate or contamination rate between sampling techniques.

\section{Discussion}

This diagnostic accuracy review is the first to assess the available evidence from different urine sampling techniques on symptomatic patients with suspected UTI in primary care. Overall, we did not find consistent evidence to suggest important differences in diagnostic accuracy among the included urine sampling techniques (MSCC, MSU or random voiding). The slightly lower specificity of voided samples compared to invasive sampling techniques (suprapubic puncture and catheter) will cause $5-10 \%$ of healthy patients to be overdiagnosed. This does not, in our opinion, outweigh the discomfort and risk of complications associated with sterile techniques. The quality of the studies was

Table 3 MCSS vs. sterile samples

\begin{tabular}{|c|c|c|c|c|c|c|c|c|c|c|c|}
\hline Study & Cut-off & $\mathrm{n}$ & TP & TN & $\mathrm{FN}$ & FP & $\operatorname{PPV}(95 \% \mathrm{CI})$ & $\mathrm{NPV}(95 \% \mathrm{Cl})$ & $\operatorname{SEN}(95 \% \mathrm{Cl})$ & SPE $(95 \% \mathrm{CI})$ & Sensitivity $(95 \% \mathrm{Cl}) \quad$ Specificity $(95 \% \mathrm{Cl})$ \\
\hline Walter 1989 & $\geq 10^{5} \mathrm{cfu} / \mathrm{ml}$ & 105 & 41 & 61 & 1 & 2 & $0,95(0,83-0,99)$ & $0,98(0,90-1,00)$ & $0,98(0,86-1,00)$ & $0,97(0,88-0,99)$ & $\rightarrow$ \\
\hline Mabeck 1969 & $\geq 10^{4} \mathrm{cfu} / \mathrm{ml}$ & 95 & 39 & 52 & 0 & 4 & $0,91(0,77-0,97)$ & $1,00(0,91-1,00)$ & $1,00(0,89-1,00)$ & $0,93(0,82-0,98)$ & $\rightarrow$ \\
\hline Hooton 2013 & $\geq 10 \mathrm{cfu} / \mathrm{ml}$ & 202 & 141 & 44 & 1 & 16 & $0,90(0,84-0,94)$ & $0,98(0,86-1,00)$ & $0,99(0,96-1,00)$ & $0,73(0,60-0,84)$ & $\rightarrow-$ \\
\hline Stamm 1982 & $\geq 10 \mathrm{cfu} / \mathrm{ml}$ & 187 & 98 & 63 & 0 & 26 & $0,79(0,71-0,86)$ & $1,00(0,93-1,00)$ & $1,00(0,95-1,00)$ & $0,71(0,60-0,80)$ & $\rightarrow$ \\
\hline & & & & & & & & & & & $\begin{array}{lllllllllllll}0 & 0.2 & 0.4 & 0.6 & 0.8 & 1 & 0 & 0.2 & 0.4 & 0.6 & 0.8 & 1\end{array}$ \\
\hline
\end{tabular}

Detailed legend: Diagnostic accuracy of mid-stream-clean-catch samples vs. urethral catheterization/suprapubic puncture. $95 \%$ confidence intervals in brackets. A cut-off of $\geq 10^{4} \mathrm{cfu} / \mathrm{ml}$ has been chosen in the study by Mabeck. TP True positives; TN True negatives; FN False negatives; FP False positives; PPV Positive predictive value; NPV Negative predictive value; SEN Sensitivity; SPE Specificity 
Table 4 Home-voided samples vs. MSCC

\begin{tabular}{|c|c|c|c|c|c|c|c|c|c|c|c|}
\hline Study & Cut-off & $\mathrm{n}$ & TP & TN & FN & FP & PPV & NPV & SEN & SPE & $35 \%$ \\
\hline Baerheim 1990 & $\geq 10^{4} \mathrm{cfu} / \mathrm{ml}$ & 73 & 48 & 15 & 6 & 4 & $0,92(0,81-0,98)$ & $0,71(0,48-0,88)$ & $0,89(0,77-0,95)$ & $0,79(0,54-0,93)$ & $\Longrightarrow$ \\
\hline & & & & & & & & & & & $\begin{array}{lllllllllllll}0 & 0.2 & 0.4 & 0.6 & 0.8 & 1 & 0 & 0.2 & 0.4 & 0.6 & 0.8 & 1\end{array}$ \\
\hline
\end{tabular}

Detailed legend: Diagnostic accuracy of home-voided samples vs. mid-stream-clean-catch samples. $95 \%$ confidence intervals in brackets. TP True positives; TN True negatives; FN False negatives; FP False positives;

PPV Positive predictive value; NPV Negative predictive valuxe; SEN Sensitivity; SPE Specificity

moderate and substantial heterogeneity was present between study designs and applied diagnostic cut-offs. With the available evidence, each general practitioner can choose freely the sampling technique most appropriate for his or her practice and patients.

The current review included two studies from general practice and 5 from outpatient clinics or student clinics. Participants were symptomatic patients under investigation for urinary tract infection. We have no reason to suspect the included patients differ from the average UTI patient in primary care. Thus we believe the results can be considered applicable to most primary care settings including general practice.

The included methods of urine sampling included, the different cut-offs for infection applied and the time span between studies of up to 50 years does however suggest that the overall results regarding their diagnostic accuracy should be considered with caution.

The current consensus regarding a cut-off for infection (eg. $10^{3} \mathrm{cfu} / \mathrm{ml}$ for primary uropathogens) was not directly assessed in any of the studies, but we calculated the sensitivity and specificity based on the two studies by Mabeck and Stamm. While the sensitivity was above 0.80 in both studies, the specificity differed between studies and was low (0.59) in the study by Mabeck. However, this could be a chance finding and caution should be excised when interpreting these results as they are based on few older studies and we do not know if this result would still apply today with current microbiological procedures. Furthermore, current cut-offs are based on microbiological assessments and have, to our knowledge, never been validated in relation to patient-relevant outcomes like cure-rate or impact on daily activities. The development of such patient-centred outcomes may be more applicable to a general practice setting.

The European urine analysis guideline recommends a MSCC without detergents [12]. However, this guideline is based on studies including pregnant, asymptomatic as well as hospitalized patients and their conclusions do not necessarily apply to the average patient in general practice. Studies based in secondary care have found varying accuracy of voided urine samples depending on their patient group, design and gold standard [14-18]. However, studies investigating symptomatic, otherwise healthy women seem to essentially reproduce our findings $[19,20]$.

\section{Conclusions}

The present review does not present evidence to suggest one urine sampling technique over another according to diagnostic performance; rather this should at present depend on ease of use and convenience for patients and practices. This lack of evidence is in part due to few available studies and further testing on current diagnostic cutoffs as well as new patient-centred outcomes is warranted.

\section{Appendix A \\ Search Strings \\ SEARCH:}

Search string Medline 01.01.1971 - 31.05.2015: ("Urinary Tract Infections"[Mesh] OR "Cystitis"Mesh OR "Urinary Tract Infection*" OR Cystitis OR "Bacteriuria"Mesh OR Bacteriuria) AND (Urine OR "Urine"Mesh]) AND ("Specimen Handling"[Mesh] OR "Urinalysis"[Mesh] OR "Urine Specimen Collection"Mesh+ OR Collection OR midstream OR "clean catch") NOT("Animals"[Mesh] NOT "Humans"Mesh]) NOT "Pregnancy"Mesh NOT "Child”[Mesh] NOT "Infant"[Mesh] NOT "Male"[Mesh]

Search string Medline 01.01.1955 - 31.12.1970: ("Urinary Tract Infections"[Mesh] OR "Cystitis"[Mesh] OR "Urinary Tract Infection*" OR Cystitis OR "Bacteriuria"[Mesh] OR Bacteriuria) AND (Urine OR "Urine"[Mesh]) AND ("Specimen Handling"[Mesh] OR "Urinalysis"[Mesh] "Urine Specimen Collection"[Mesh] OR Collection OR midstream OR "clean catch" OR "Urine/microbiology" [Mesh]) NOT(“Animals"[Mesh] NOT “Humans”[Mesh]) NOT "Pregnancy"[Mesh] NOT “Child”[Mesh] NOT "Infant"[Mesh] NOT "Male"[Mesh]

Search string Embase: (urinary tract infection/or cystitis.mp. or cystitis/or bacteriuria/or bacteriuria.mp.) And (urine/or urine.mp.) And (collection or specimen or midstream).af. And (woman or women or female).af.

Filter: Language $=$ English, Swedish, Danish, Norwegian

Table 5 Randomized controlled trials and infection rates

\begin{tabular}{llllll}
\hline Study & Technique & Patients (n) & Incidence & Index infected (95\% Cl) & Reference infected (95 \% Cl) \\
\hline Bradbury 1988 & MSU vs. MSCC & 158 & $0.25(0.18-0.31)$ & $0.25(0.14-0.35)$ & $0.25(0.16-0.34)$ \\
Lifshitz 2000 & Random vs. MSCC & 242 & $0.55(49-61)$ & $0.57(0.46-0.68)$ & $0.53(0.45-0.61)$ \\
\hline
\end{tabular}

Detailed legend: Infection rates in randomized controlled trials included in the review. 95 \% confidence intervals in brackets. MSCC mid-stream clean catch; MSU Mid-stream urine; Random random sample without instruction 


\section{Appendix B}

Table 6 Complete list of excluded studies

\begin{tabular}{|c|c|c|c|c|c|}
\hline Title & Author & Year & Identified & Excusion & Excluded after \\
\hline $\begin{array}{l}\text { Abnormal urinalysis results are common, regardless of } \\
\text { specimen collection technique, in women without urinary } \\
\text { tract infections. }\end{array}$ & $\begin{array}{l}\text { Frazee B.W. Enriquez K. } \\
\text { Ng V. Alter H. }\end{array}$ & 2015 & Embase & Wrong group & Abstract \\
\hline $\begin{array}{l}\text { A midstream urine collector is not a good alternative to a } \\
\text { sterile collection method during the diagnosis of urinary tract } \\
\text { infection. }\end{array}$ & $\begin{array}{l}\text { Verliat-Guinaud J, Blanc P, } \\
\text { Garnier F, Gajdos V, Guigonis V. }\end{array}$ & 2015 & Medline & Wrong group & Abstract \\
\hline $\begin{array}{l}\text { Re: Voided midstream urine culture and acute cystitis in } \\
\text { premenopausal women. }\end{array}$ & Schaeffer E.M. & 2014 & Embase & $\begin{array}{l}\text { Commentary/ } \\
\text { review }\end{array}$ & Abstract \\
\hline $\begin{array}{l}\text { Associations between individual lower urinary tract symptoms } \\
\text { and bacteriuria in random urine samples in women. V. }\end{array}$ & $\begin{array}{l}\text { Sorrentino F, Cartwright R, } \\
\text { Digesu GA, Tolton L, Franklin L, } \\
\text { Singh A, Greco P, Khullar V }\end{array}$ & 2014 & Medline & Wrong setting & Abstract \\
\hline Infection: Utility of midstream urine cultures questioned. & Payton S. & 2014 & Medline & $\begin{array}{l}\text { Commentary/ } \\
\text { review }\end{array}$ & Abstract \\
\hline $\begin{array}{l}\text { Voided midstream urine culture is a good test for acute } \\
\text { cystitis in premenopausal women. }\end{array}$ & Cox L, Clemens JQ. & 2014 & Medline & $\begin{array}{l}\text { Commentary/ } \\
\text { review }\end{array}$ & Article \\
\hline $\begin{array}{l}\text { Easy peezy: A patient satisfaction survey on an innovative } \\
\text { device for collection of mid-stream urine (MSU) samples. }\end{array}$ & Khorsandi M. Hussain B. Chow W. & 2013 & Embase & Wrong design & Abstract \\
\hline ezy at ease: Our initial 106 patients ex & low W.M. Hussain B & 2013 & Embase & Wrong design & Abstract \\
\hline
\end{tabular}
innovative device for collection of Mid-Stream Urine (MSU) samples.

Effect of urogenital cleaning with paper soap on bacterial contamination rate while collecting midstream urine specimens

Urine collection in the emergency department: what really happens in there?

Urine specimen collection: how a multidisciplinary team improved patient outcomes using best practices.

"Mixed growth of doubtful significance" is extremely significant in patients with lower urinary tract symptoms.

The impact of improperly collected urine cultures on patient treatment in the emergency department.

Managing UTI in primary care: should we be sending midstream urine samples?

A comparative study on bacterial cultures of urine samples obtained by clean-void technique versus urethral catheterization.

Comparison of sampling methods for urine cultures.

Effect of perineal cleansing on contamination rate of mid-stream urine culture.

Obtaining a catheter specimen of urine.

Taking a midstream specimen of urine.

A novel midstream urine-collection device reduces contamination rates in urine cultures amongst women.

Catheter specimens of urine: an audit of practice.

Contamination of urine specimens did not differ with collection technique in women with acute dysuria.

Collection and transport of urine for culture.
Gilbert R.

Gilbert R.

UnI $\tilde{A}^{1} / 4$ H, Sardan YC, Ulker S

2007 Medline

2006 Medline

2006 Medline

Shrestha R, Gyawali N, Gurung R, 2013 Medline Amatya R, Bhattacharya SK. White DE, Alter $\mathrm{H}$.

Sathiananthamoorthy S.

Swamy S. Kupelian A. Horsley H.

Gill K. Collins L. Malone-Lee J.

2012 Embase

2010 Medline

2007 Medline

Lau AY, Wong SN, Yip KT, Fong KW, Li SP, Que TL.

Blake DR, Doherty LF.

2006 Medline

2005 Embase Kearney P. Weatherall R.

Gilbert R, Henderson S.

Lifshitz E. Kramer L.

2005 Medline

2001 Embase

Perera CU.
2001 Medline
Frazee BW, Frausto K, Cisse B,
Wrong setting Article

Wrong setting Abstract

Wrong setting Abstract

Wrong design Abstract

Wrong design Abstract

Commentary/ Abstract review

Wrong group Abstract

Wrong setting Abstract Wrong group Abstract

Commentary/ Article review

Commentary/ Abstract review

Wrong group Abstract

Wrong design Abstract

Commentary/ Abstract review

Commentary/ Abstract review 
Table 6 Complete list of excluded studies (Continued)

Honey jars and diagnosis of urinary tract infections-ascent quality work.

A technique for collection of uncontaminated urine for culture from female patients.

The midstream muddle.

Urine collection and culture in elderly people.

A simple and efficient urine sampling method for bacteriological examination in elderly women.

Assessment of urine collection technique for microbial culture.

Collecting clean-catch urine in the nursing home: obtaining the uncontaminated specimen.

Bacteriuria-sampling methods and significance.

Collection of urine for culture.

Does a clean-catch urine sample reduce bacterial contamination?

Urine sampling technique

Evaluation of urine sampling technique: bacterial contamination of samples from women students

Bacteriological findings in urine specimens from women. Association with urinary tract symptoms and sampling methods.

Perineal cleansing and midstream urine specimens in ambulatory women

Urine sampling in ambulatory women.

An approach to urinary tract infections in ambulatory women

Laboratory diagnosis of urinary tract infection in ambulatory women.

Clean-catch versus straight-catheter urinalysis results in women.

Validity of urinary catheter specimen for diagnosis of urinary tract infection in the elderly.

Is the Clean-Catch Midstream Void Procedure Necessary for Obtaining Urine Culture Specimens from Men?

Comparison of mid catheter collection and suprapubic aspiration of urine for diagnosing bacteriuria due to fastidious micro-organisms.

\section{THE MYTH OF THE CLEAN CATCH URINE SPECIMEN}

[Diagnosis of urinary infections by the transportable agar method. Collection of urine in non-sterile containers].

An automatic midstream urine collector.

Perineal cleansing before midstream urine, a necessary ritual.

Comparison of paired midstream voided and catheterized urine samples from female patients in a general hospital.

New method for obtaining uncontaminated urine from women.
Forsum U

Gleason D.M. Bottaccini M.R. Reilly R.J. McNeill J.

Bannatyne RM.

Clague J, Horan M.

Michielsen WJ, Geurs FJ,

Verschraegen GL, Claeys GW, Afschrift MB.

Prandoni $\mathrm{D}$, Boone $\mathrm{MH}$, Larson $\mathrm{E}$, Blane CG, Fitzpatrick H.

Brazier A.M. Palmer M.H.

Pfau A.

Jaffe JS.

Leisure MK, Dudley SM,

Donowitz LG.

Curtis P, Kim-Foley S, Kebede M

Baerheim A (1), Digranes A,

Hunskaar S.

Baerheim A, Digranes A,

Hunskaar S, Laerum E.

Holliday G, Strike PW,

Masterton RG

Walter FG

Ronald AR, Conway B

Latham R.H. Wong E.S. Larson A.

Guss DA, Dunford JV, Griffith LD, Neuman TS, Baxt WG, Winger B, Gruber SL.

Grahn D, Norman DC, White ML, Cantrell M, Yoshikawa TT.

Lipsky BA, Inui TS, Plorde JJ, Berger RE.

Savige JA, Birch DF, Fairley KF.

Immergut MA, Gilbert EC, Frensilli FJ, Goble M

Svendsen I, Eklund A

King MR.

Morris RW, Watts MR, Reeves DS.

Barnes WF, Albers DD.

Cade R, Raulerson JD,

Mahoney JJ, Duprey P, Privette $M$

Phelan MC, Beers H, Fuller TJ,

Juncos LI, Grubb WG.

\section{Embase}

1994 Medline

1994 Medline
2001 Medline
Wrong design Article
2000 Embase
Wrong group Article
2000 Medline
Commentary/ Abstract
review
1998 Medline Wrong design Article
1997 Medline Wrong group Article

$\begin{array}{lll}1996 \text { Medline } & \text { Wrong group Article } \\ 1995 \text { Embase } & \begin{array}{l}\text { Commentary/ Abstract } \\ \text { review }\end{array} \\ 1994 \text { Medline } & \text { Wrong design Article } \\ 1994 \text { Medline } & \begin{array}{l}\text { Commentary/ Abstract } \\ \text { review }\end{array} \\ 1993 \text { Medline } & \begin{array}{l}\text { Wrong group Article } \\ 1993 \text { References Commentary/ Article } \\ \end{array} & \end{array}$

1992 References Wrong group Article

1991 Medline Wrong design Abstract

1991 References Wrong group Article

1990 Medline Duplicate Abstract

1988 References Commentary/ Article review

1985 Embase Wrong design Abstract

1985 Medline Wrong design Article

1985 Medline Wrong group Abstract

1984 References Wrong group Article

1983 Medline Wrong setting Article

1981 References Wrong group Article

1980 Medline Wrong design Article

1980 Medline Wrong setting Article

1979 Medline Missing data Article

1978 Medline Wrong group Article

1978 Medline Wrong group Abstract 
Table 6 Complete list of excluded studies (Continued)

Comparison of paired midstream voided and catheterized urine sam- ples from female patients in a general hospital.

Qualitative assessment of midstream urine cultures in the detection of bacteriuria.

Bacterial contamination of urine, collected in fractions from different phases of micturition. A study in healthy women.

Correlation of a new urine collection-culture tube with the standard loop technique.

[Examination of the urine. Collection, transport and quantitative bacteriological assessment]

Suprapubic bladder aspiration in diagnosis of urinary tract infection.

Reliability of clean-voided mid-stream urine specimens for the diagnosis of significant bacteriuria in the female patient.

Voided urine cultures in women. A study of 425.

The collection of urine for bacteriological investigation.

The collection and assessment of midstream urine samples in the diagnosis of urinary tract infection in women.

A screening method for the evaluation of urinary tract infections in female patients without catheterization.

Sterile-voided urine culture; an evaluation in 100 consecutive hospitalized women.

A comparison of bac-terial counts of the urine obtained by needle aspiration of the bladder, catheter- ization and midstream-voided methods

A screening method for the evaluation of urinary tract infections in female patients without catheterization

The case against the catheter

Barnes WF, Albers DD

Gower P.E. Roberts A.P.

Henning C, Tornvall G.

Martin LP, Ahmed M.

Vejlsgaard R.

Bailey RR, Little PJ.

Lemieux G, St-Martin M.

Breitenbucher BR.

Craig I.

DAWBORN JK, PLUNKETT PJ.

BOSHELL BR, SANFORD JP

MERRITT AD, SANFORD JP.

Monzon OT, Ory EM,

Dobson HL, Carter E, Yow EM

Boswell BR, Sanford JP

BEESON, P B

BEESON, P B
1978 References Wrong group Article

1975 Embase

Wrong group Abstract

1975 Medline Wrong group Abstract

1974 Medline Wrong setting Article

1969 Medline Commentary/ Article review

1969 Medline Wrong design Article

1968 Medline Wrong setting Article

1966 Medline Wrong setting Article

1965 Medline Wrong setting Article

1963 Medline Wrong setting Article

1958 Medline Wrong group Article

1958 Medline Wrong setting Article

1958 References Wrong setting Article

1958 References Wrong setting Article

1958 References Commentary/ Article review

1956 References Wrong group Article

\section{Additional file}

Additional file 1: Quadas-2. (PDF 427 kb)

\section{Abbreviations}

FN, false negatives; FP, false positives; MSCC, mid-stream-clean-catch technique; MSU, mid-stream urine; NPV, negative predictive value; PPV, positive predictive value; $R C T$, randomized controlled trials; SEN, sensitivity; SPE, specificity; TN, true negatives; TP, true positives; UTI, urinary tract infection

\section{Acknowledgements}

We would like to thank Niels Frimodt-Møller and Chris Del Mar for their suggestions for supplementary literature and the UC CARE cooperation for setting higher standards in the fight against antibiotic resistance.

\section{Funding}

This study was funded by UC CARE, University of Copenhagen.

\section{Availability of data and materials}

Complete list of excluded studies and full quality evaluation can be found in appendices. For additional data, please contact the corresponding author.

\section{Authors' contributions}

The literature search and inclusion of studies was performed by $\mathrm{AH}$. Both authors performed the data extraction and quality assessment. Both authors have critically revised the manuscript and approved the final version.

\section{Authors' information}

Anne Holm: Medical Doctor and PhD-fellow at The Research Unit for General Practice and Section of General Practice, Department of Public Health, University of Copenhagen, Denmark.

Rune Aabenhus: General Practitioner and PhD-fellow at The Research Unit for General Practice and Section of General Practice, Department of Public Health, University of Copenhagen, Denmark.

\section{Competing interests}

The authors declare that they have no competing interests.

\section{Consent for publication}

Not applicable.

Ethics approval and consent to participate

Not applicable.

\section{PRISMA guidelines}

The authors declare, they have followed the PRISMA Guidelines in conducting this study.

Received: 19 October 2015 Accepted: 23 May 2016

Published online: 08 June 2016 


\section{References}

1. Forskningsenheden for Almen Praksis Aarhus Universitet, Afdeling for Almen Medicin Aarhus Universitet: Kontakt- Og Sygdomsmønsterundersøgelse KOS 2008. 2008.

2. Lifshitz E, Kramer L. Outpatient urine culture: does collection technique matter? Arch Intern Med. 2000;160:2537-40.

3. Jaffe JS. Collection of urine for culture. N Engl J Med. 1994;331:617-8.

4. Payton S. Infection: Utility of midstream urine cultures questioned. Nat Rev Urol. 2013;11:3-3.

5. Smith G. Diagnosis of coliform infection in acutely dysuric women. N Engl J Med. 1983;309:1393-4.

6. Whiting PF, Rutjes AWS, Westwood ME, Mallet S, Deeks JJ, Reitsma JB, Leeflang MMG, Sterne JAC, Bossuyt PMM. QUADAS-2: a revised tool for the quality assessment of diagnostic accuracy studies. Ann Intern Med. 2011:155:529-36.

7. Hooton TM, Roberts PL, Cox ME, Stapleton AE. Voided midstream urine culture and acute cystitis in premenopausal women. N Engl J Med. 2013;369:1883-91.

8. Stamm W, Counts $G$. Diagnosis of coliform infection in acutely dysuric women. N Engl J Med. 1982;307:463-8.

9. Walter F, Knopp R. Urine sampling in ambulatory women: midstream clean-catch versus catheterization. Ann Emerg Med. 1989;18:166-72.

10. Mabeck C. Studies in urinary tract infections. The diagnosis of bacteriuria in women. Acta Med Scand. 1969;186:35-8.

11. Baerheim A, Laerum E. Home-voided urine specimens in women. Diagnostic agreement with clean-catch midstream specimens. Scand J Prim Health Care. 1990:8:207-11.

12. Aspevall $\mathrm{O}$, Hallander $H$, Gant $V$, Kouri T. European guidelines for urinalysis: a collaborative document produced by European clinical microbiologists and clinical chemists under ECLM in collaboration with ESCMID. Scand J Clin Lab Invest. 2000;60:1-96.

13. Bradbury SM. Collection of urine specimens in general practice: to clean or not to clean? J R Coll Gen Pract. 1988:38:363-5.

14. Dawborn JK, Plunkett PJ. The collection and assessment of midstream urine samples in the diagnosis of urinary tract infection in women. Med J Aust. 1963;50:540-3

15. Barnes WF, Albers DD. Comparison of paired midstream voided and catheterized urine samples from female patients in a general hospital. J Okla State Med Assoc. 1978;71:82-4.

16. Craig I. The collection of urine for bacteriological investigation. $\mathrm{Br} J \mathrm{Clin}$ Pract. 1965;19:557-63.

17. Prandoni D, Boone MH, Larson E, Blane CG, Fitzpatrick H. Assessment of urine collection technique for microbial culture. Am J Infect Control. 1996;24:219-21.

18. Merritt A, Sanford J, Durham N. Sterile-voided urine culture; an evaluation in 100 consecutive hospitalized women. J Lab Clin Med. 1958;52:463-70.

19. Lemieux G, St-Martin M. Reliability of clean-voided mid-stream urine specimens for the diagnosis of significant bacteriuria in the female patient. Can Med Assoc J. 1968:98:241-5.

20. Shrestha R, Gyawali N, Gurung R, Amatya R, Bhattacharya SK. Effect of urogenital cleaning with paper soap on bacterial contamination rate while collecting midstream urine specimens. J Lab Physicians. 2013;5:17-20.

\section{Submit your next manuscript to BioMed Central and we will help you at every step:}

- We accept pre-submission inquiries

- Our selector tool helps you to find the most relevant journal

- We provide round the clock customer support

- Convenient online submission

- Thorough peer review

- Inclusion in PubMed and all major indexing services

- Maximum visibility for your research

Submit your manuscript at www.biomedcentral.com/submit 